https://doi.org/10.7559/gestaoedesenvolvimento.2019.385

Data de receção: 30/08/2018

Data de aceitação: 11/07/2019

\title{
CUIDADORES FORMAIS DE IDOSOS INSTITUCIONALIZADOS: PERCEÇÕES E SATISFAÇÃO PROFISSIONAL
}

\section{FORMAL CAREERS OF INSTITUTIONALIZED ELDERLY: PERCEPTIONS AND PROFESSIONAL SATISFACTION}

\author{
Magda Guerra ${ }^{1}$ orcid.org/0000-0002-7229-0858 \\ Isabel Martins ${ }^{2}$ \\ Dina Santos ${ }^{3}$ \\ Veiga, $J^{4}$ \\ Moitas, R. ${ }^{4}$ \\ Silva; R. $^{4}$
}

\begin{abstract}
Resumo
Introdução: Resultante do crescente envelhecimento demográfico $e$ do aumento da esperança média de vida, a institucionalização do idoso representa nos dias de hoje uma problemática emergente. Consideramos por isso pertinente estudar o perfil do cuidador formal de idosos institucionalizados e a sua satisfação profissional no intuito de melhorar a qualidade dos cuidados prestados. Objetivo: Delineouse como objetivo principal identificar as representações que os cuidadores formais têm acerca do cuidado prestado ao idoso
\end{abstract}

1 Doutoranda em Enfermagem - UCP- Porto (ICS); Membro da Unidade de Investigação-RECI; Professora Assistente Instituto Piaget; Mestre em Gestão e Especialização em Gestão e Administração de Unidades de Saúde; Enfermeira Especialista em Enfermagem Médico Cirúrgica; Centro Hospitalar Tondela-Viseu, Portugal. E-mail: magdasantosguerra@gmail.com

${ }^{2}$ Mestre em Gestão e Especialização em Gestão e Administração de Unidades de Saúde; Especialista em Enfermagem de Saúde Materna, Obstetrícia e Ginecologia; USF - Infante D. Henrique, Viseu, Portugal.

${ }^{3}$ Enfermeira Especialista em Enfermagem Médico Cirúrgica; Unidade de Cuidados na Comunidade, Viseu, Portugal.

${ }^{4}$ Estudantes do Curso de Licenciatura em Enfermagem. 


\section{Magda Guerra, Isabel Martins, Dina Santos, J. Veiga, R. Moitas,} R. Silva

institucionalizado. Metodologia: Estudo qualitativo através da análise de conteúdo das unidades de registo. $O$ instrumento de recolha de dados utilizado foi a entrevista semiestruturada. A amostra foi constituída por doze cuidadoras formais de uma instituição de idosos da zona centro do país. Resultados: Os significados atribuídos pelas cuidadoras do que é ser idoso foram: uma pessoa merecedora de respeito, com sabedoria, que precisa de afeto e cuidados, que voltar a ser criança e pessoa com limitações físicas. Por cuidar, entendem dar carinho/apoio, transmitir confiança, um bem essencial, cuidar do corpo, mente e coração e ainda, saber escutar. A relação das cuidadoras com os idosos pauta-se pela alegria e boa disposição, uma relação de respeito pela individualidade/vontade da pessoa idosa, tentar adaptar-se à personalidade de cada um. Executam frequentemente os cuidados de higiene (fazer a barba); vestir/despir; levantar/deitar; posicionar; cuidados da alimentação/hidratação; atividades lúdicas e apoio na deambulação dos idosos. É no transporte e posicionamento dos idosos que sentem maiores dificuldades. Na maioria dos casos, as entrevistadas referem que o seu trabalho é apreciado por todos (idosos, família e direção). Para algumas cuidadoras o que lhes dá maior satisfação é sentirem que os idosos estão contentes/confortáveis. Conclusão: Todas as entrevistadas relataram que a atividade de cuidadora lhes traz satisfação profissional e identificaram necessidades formativas em algumas áreas do conhecimento. Os resultados resultantes desta investigação levamnos à reflexão sobre a importância da criação e monitorização de programas de ação no domínio formativo em áreas especificas adaptado à realidade de cada instituição.

Palavras-chave: Idosos Institucionalizados; Cuidador formal; Perceções; Satisfação Profissional.

\footnotetext{
Abstract

Introduction: As a result of the growing demographic aging and the increase in the average life expectancy, the institutionalization of the elderly represents an emerging problem today. We therefore consider
} 
it pertinent to study the profile of the formal caregiver of institutionalized elderly people and their professional satisfaction in order to improve the quality of care provided. Aim: It was outlined as a main objective to identify the representations that the formal caregivers have about the care provided to the institutionalized elderly. Methodology: Qualitative study through content analysis of the registration units. The data collection instrument used was the semistructured interview. The sample consisted of twelve formal caregivers from an institution of the elderly in the central zone of the country. Results: The meanings attributed by the caregivers of what it is to be old were: a person deserving of respect, with wisdom, who needs affection and care, to return to being a child and a person with physical limitations. By caring, they understand giving affection / support, transmitting trust, an essential good, caring for the body, mind and heart and also, knowing how to listen. The relationship of caregivers with the elderly is guided by joy and good disposition, a relation of respect for the individuality / will of the elderly person, trying to adapt to the personality of each one. They often perform hygiene (shaving); dressing / undressing; to raise / to lie down; position; feeding / hydration care; recreational activities and support in the deambulation of the elderly. It is in the transportation and positioning of the elderly that they experience greater difficulties. In most cases, the interviewees report that their work is appreciated by all (elderly, family and management). For some caregivers what gives them greater satisfaction is to feel that the elderly are happy / comfortable. Conclusion: All the interviewees reported that the caregiver activity brings them professional satisfaction and identified training needs in some areas of knowledge. The results of this research lead us to reflect on the importance of creating and monitoring programs of action in the field of training in specific areas adapted to the reality of each institution.

Keywords: Institutional Elderly; Formal caregiver; Perceptions; Professional Satisfaction. 


\section{INTRODUÇÃO}

Portugal constitui-se hoje como um dos países mais envelhecidos da Europa. A verdade é que nunca, em tempo algum, a esperança média de vida foi tão elevada e esta modificação demográfica, traduzida em ganhos de anos de vida, teve o seu reflexo na adoção de novos comportamentos, estilos de vida e expetativas. A nossa estrutura social está a metamorfosear e com ela, as respostas à dependência, sendo cada vez mais constante recorrer a instituições especializadas para satisfazer as necessidades da pessoa idosa pois, se ser idoso não significa ser dependente, é indiscutível, que uma maior incidência de doenças de cariz crónico e dependência funcional emergem nestas faixas etárias. Este novo paradigma social suscita a necessidade de qualificar os cuidadores formais para que prestem cuidados com melhor qualidade ao cliente institucionalizado.

Partindo-se do pressuposto de que o cuidado formal se refere àquele que é prestado a pessoas dependentes por parte de pessoas que recebem remuneração económica pelo serviço prestado, assume pertinência mencionar que o cuidado ao idoso institucionalizado tem que obedecer forçosamente a um conjunto de normas, delineadas a priori pelo regulamento da instituição onde reside, condição que poderá influenciar a satisfação no trabalho na perspetiva do cuidador e refletir-se na relação de empatia estabelecida entre o cuidador e o idoso (Chambel, 2016).

De acordo com a mesma autora, "cuidar nem sempre é uma atividade isenta de dificuldades, cuidar é promover a qualidade de vida garantindo a satisfação de um conjunto de necessidades a ela indispensáveis, mas que são diversificadas na sua manifestação e condicionadas inúmeras vezes por um conjunto de fatores" (Chambel, 2016, p. 10).

Neste sentido, o presente trabalho centra-se no cuidador formal de idosos institucionalizados, cujo objetivo geral delineado consistiu em identificar um perfil do cuidador formal de idosos institucionalizados. Procurou ainda perceber-se se os cuidadores formais possuem formação específica na área; compreender se os mesmos entendem que a formação é útil; identificar as representações sobre o cuidar/cuidado; perceber se a forma como o cuidador formal vê o idoso influencia o seu cuidado; conhecer o tipo de atividades executadas pelos cuidadores formais; 
perceber como os cuidadores formais encaram o executar das suas atividades; identificar as dificuldades mais vividas pelos cuidadores formais no exercício da sua profissão e identificar fatores de satisfação na vida dos cuidadores formais proveniente da sua profissão.

Uma abordagem holística e compreensiva da problemática do cuidar a pessoa idosa institucionalizada implica um enquadramento demográfico. Neste contexto, segundo a perspetiva de Pinto (2012), são várias as estruturas com missões que objetivam o apoio da pessoa idosa sob vários formatos. Na política social para a terceira idade em Portugal, a rede social inclui medidas inovadoras, atualizadas, preventivas, promotoras do desenvolvimento humano e redutoras da vulnerabilidade social dos idosos, com a criação de instituições de apoio ao idoso. No estudo desenvolvido por Martins e colaboradores (2015), é evocado o autor Paúl (2005) que realça a importância redes de apoio para garantir a autonomia dos idosos, um autoconceito positivo e uma maior satisfação de vida, promovendo um envelhecimento bem-sucedido.

Contudo, a institucionalização do idoso pode acarretar um grande sofrimento, visto que se vê confrontado com a separação dos seus familiares e alguns receios da perda de liberdade, abandono pelos filhos, aproximação da morte e dúvidas acerca do tratamento que irão receber. No entanto, "a institucionalização não deve ser encarada apenas pela negativa, pois existem idosos que podem sentir-se mais acompanhados, ativos e mesmo mais felizes do que quando se encontravam sós em suas casas. Neste processo de mudança, o indivíduo pode criar os seus próprios mecanismos de adaptação e desenvolver uma sensação ou sentimento de satisfação pela sua nova situação" (Ferreira, 2012, p. 19). Cabe aos profissionais das redes de apoio formal criar as condições para que os idosos sintam que a sua autonomia e participação social são tidas em consideração, fatores determinantes para um envelhecimento ativo.

O envelhecimento associado à ausência de uma rede de apoio familiar capaz de responder às necessidades de autonomia e bem-estar dos idosos, bem como da satisfação das suas necessidades básicas, levou ao advento de instituições onde o isolamento deste grupo etário passa a ser institucionalizado (Gonçalves, 2010). A saída do idoso do seu meio familiar acarreta novos processos de adaptação, que levam a um maior ou menor sofrimento. Neste sentido, o aumento do envelhecimento traduz-se 
na crescente procura de cuidados de saúde e apoio social, sobretudo por pessoas idosas com diferentes níveis de dependência funcional e cronicidade múltipla que podem persistir num tempo indeterminado, perspetivando-se, num futuro próximo, o agravamento das situações de dependência (Plano do Nacional de Saúde, 2012).

De acordo com a literatura nesta área, os cuidadores formais de idosos institucionalizados são um grupo profissional que no exercício das suas funções, tendem a desenvolver sintomatologia física e psíquica que, simultaneamente com as exigências continuadas das tarefas, levam a situações de stresse, sobrecarga e ao desenvolvimento de perturbações emocionais, nomeadamente a depressão ou a ansiedade, podendo, inclusive, resultar em burnout. A sobrecarga, o stresse e a tensão são os sintomas mais verificados nos cuidadores (Chiung-man Wu, 2009).

Estudos evidenciam a predisposição dos cuidadores formais de idosos institucionalizados ao desgaste emocional e síndromes psicopatológicos (Azevedo \& Pereira, 2010). Documentam ainda o facto de que a perceção dos cuidadores formais sobre a prestação de cuidados aos idosos seja relativamente afetada pelo seu próprio estado emocional, a sobrecarga de cuidado, o seu senso de autoeficácia, a qualidade do seu relacionamento com os idosos (Bauab, 2013).

Neste sentido, Sequeira (2010) refere que cuidar de uma pessoa com dependência interfere com aspetos da vida pessoal, familiar e laboral dos cuidadores formais. As principais dificuldades apresentadas pelos cuidadores formais de idosos institucionalizados são: a interação com o idoso; o desconhecimento da doença; a falta de tempo e de recursos humanos; o impacto emocional e físico; a dificuldade de organização; o planeamento de atividades e a interação com a família dos idosos.

Desta forma, os desafios no âmbito da promoção do envelhecimento ativo e da promoção da saúde dos cuidadores formais de idosos institucionalizados requer um maior investimento na formação dos técnicos envolvidos na prestação de cuidados aos idosos (Sequeira, 2010).

\section{METODOLOGIA}

O presente estudo segue uma investigação qualitativa, uma vez que os dados foram recolhidos no ambiente natural em que as ações ocorrem, 
descrevendo situações vividas pelas cuidadoras de idosos institucionalizados com recurso à entrevista semiestruturada, cujas respostas obtidas foram alvo de análise de conteúdo e divididas em categorias e subcategorias de acordo com os princípios de Bardin (2015), do tipo não experimental e transversal.

A investigação em curso procurou dar resposta à seguinte questão norteadora: Quais as representações dos cuidadores formais sobre o cuidado prestado a idosos institucionalizados?

A população alvo deste estudo corresponde a um grupo representativo de cuidadores formais de 40 idosos institucionalizados num Lar de Terceira Idade de Viseu, tratando-se de uma amostra do tipo não probabilístico por conveniência cuja seleção teve em conta os seguintes critérios de inclusão: ter mais de 18 anos de idade; exercer função na instituição há mais de um ano e participar voluntariamente no estudo.

Para a aplicação das entrevistas foi efetuado um pedido de autorização ao Conselho de Administração do Lar visado onde era referenciado o responsável pela pesquisa, explicitados os objetivos e finalidade do estudo. Para além, do pedido formal à instituição, foi apresentado aos inquiridos o documento de consentimento informado para a audiogravação e para publicitar os dados recolhidos garantindo o anonimato e confidencialidade bem como a liberdade de em qualquer altura poderem desistir se assim o desejassem. Assim, participaram neste estudo doze cuidadoras formais.

As entrevistas foram realizadas pelos autores do estudo, gravadas em suporte áudio e posteriormente transcritas para suporte de papel durante os meses de novembro e dezembro de 2018. Para garantir o anonimato das entrevistadas, atribuiu-se-lhes um código, como, por exemplo: E1 que equivalente à entrevistada1. A estrutura da entrevista descrita no anexo I.

\section{APRESENTAÇÃO DOS RESULTADOS}

A amostra em estudo é constituída por doze inquiridos num universo de 15, todos do género feminino, maioritariamente com idades compreendidas entre os 50 e os 55 anos, seguindo-se aqueles com idade entre os 35 e 39 anos e por fim, dois entre 40 e os 44 anos e outros dois entre os 45 e os 49 anos. Quanto ao estado civil, onze das entrevistadas referiram ser casadas e apenas uma respondeu ser solteira. As habitações 
literárias predominantes correspondem ao $6^{\circ}$ ano $(n=8)$, seguindo-se o $12^{\circ}$ ano $(n=3)$ e apenas uma entrevistada possui o $9^{\circ}$ ano. Relativamente aos anos de serviço naquele lar, a maioria das inquiridas referiu trabalhar há 15-20 anos $(n=8)$, depois aquelas com 5-9 anos de serviço $(n=3)$ e depois com 10-14 anos de serviço apenas uma cuidadora formal.

No que concerne à primeira categoria "formação do cuidador", verificamos que, a maioria das entrevistadas decidiram trabalhar na área por necessidade de emprego $(n=8)$ e as restantes mencionaram que foi por gosto. Verificou-se que todas as entrevistadas têm formação na área, nomeadamente: animação sociocultural, geriatria, comunicação interpessoal, primeiros socorros, posicionamentos e alimentação, Doença de Alzheimer e Parkinson. Todas as entrevistadas consideram a formação útil para abordar/cuidar os idosos, reforçando que a formação ajuda a proporcionar o bem-estar dos idosos e dos próprios cuidadores. De igual modo, todas as entrevistadas revelaram apreço por apostar mais na sua formação, mais concretamente nas seguintes áreas: higiene $(n=4)$, Doença de Alzheimer/demência $(n=11)$, Suporte Básico de Vida e primeiros socorros $(n=5)$, cuidados paliativos $(n=11)$ e cuidados em geral $(n=1)$.

Quanto à caraterização das "conceções de cuidar/cuidado ao idoso", foram vários pontos de vista verbalizados para cada subcategoria. Para a maioria das entrevistadas ser idoso é alguém com sabedoria merecedor de respeito $(n=6)$, seguindo-se o significado voltar a ter tudo tal como quando se era novo $(n=2)$, tal como o de uma pessoa que precisa de afeto e cuidados $(n=2)$, apenas uma inquirida comparou o idoso a uma criança e uma outra caraterizou-o como uma pessoa com limitações físicas. As entrevistadas foram questionadas sobre o conceito de cuidar, a maioria respondeu que seria dar carinho/apoio $(n=8)$, outras responderam que seria um momento de transmissão de confiança $(n=3)$ e ainda como um ato de cuidar do corpo, mente e coração do outro $(n=1)$. Ainda para a categoria supracitada, solicitamos a descrição da relação da cuidadora formal com o idoso. Maioritariamente foi referido uma relação de alegria e boa disposição $(n=7)$, seguindo-se, em termos de representatividade, uma relação de respeito pela individualidade/vontade do idoso $(n=4)$ e por último, uma relação que privilegia o cuidar holístico $(n=1)$. Quando à 
forma como as entrevistadas acham que a população em geral pensa sobre velho/velhice, a maioria associou a pessoa reformada $(n=8)$ e minoritariamente associado a pessoa com limitações nas suas capacidades $(n=4)$.

Relativamente à terceira categoria referente às atividades executadas, constatamos que todas $(n=12)$ referiram que fazem um pouco de tudo, desde cuidados de higiene, vestir/despir, levantar/deitar, atividades lúdicas, alimentação do idoso e ajudar no transporte e deambulação do idoso. Em conformidade com os testemunhos das entrevistadas, as atividades que mais prazer lhes dão realizar nos cuidados prestados aos idosos são as atividades lúdicas $(n=5)$, seguindo-se a alimentação $(n=4)$, depois os cuidados de higiene $(n=3)$. Em relação às atividades nas quais as cuidadoras entrevistadas sentem mais dificuldades, verificamos que estas variam entre o transporte dos idosos $(n=6)$ e o posicionar $(n=6)$.

As dificuldades sentidas no exercício da sua profissão, foi outro item avaliado no presente estudo. Foi unanime a maior dificuldade relativa à falta de cooperação entre as colegas. Quanto ao momento mais complicado com que as entrevistadas se depararam, foi nos revelado pela maioria a culpabilização de má prestação de cuidados por falta de tempo $(n=6)$. Quatro das entrevistadas referiram que sentiram mais dificuldades perante a queda de um idoso, uma referiu que foi perante um engasgamento e ainda uma outra referiu a primeira vez que teve de dar banho ao idoso.

A categoria satisfação profissional objetiva identificar fatores/variáveis de satisfação das cuidadoras provenientes da sua vida profissional. Quanto à forma negativa que a sua profissão pode influenciar sua vida privada, contatamos que o facto de trabalhar por turno muitas vezes priva-a de estar mais tempo com os seus filhos $(n=6)$, pode levar ao desenvolvimento de doenças $(n=3)$ e as restantes três entrevistadas referiram influencia positiva na sua vida pessoal. Verificamos também que a atividade de cuidadora traz satisfação pessoal para todos os inquiridos $(n=12)$, alegando que gostam do que fazem, porque está implícito o "instinto de ajudar e cuidar", é uma profissão "gratificante", é uma oportunidade para 
aprender com os idosos "as coisas que eles nos dizem, o que eles viveram, o que passaram" e pelo carinho que recebem em troca. Relativamente à perceção que as cuidadoras têm do seu trabalho ser apreciado pelo idoso e pela família, todas afirmaram que por parte do idoso $\operatorname{sim}(n=12)$, já por parte da família, sete das inquiridas referiram que sim, mas cinco responderam que não seria apreciado pela família do idoso. No que concerne à perceção da direção e restante equipa, são sete os relatos que evidenciam o reconhecimento do seu trabalho, enquanto cinco revelam desconhecimento dessa perceção. Quanto ao sentimento verbalizado por prestar cuidados a idoso, foi unanime que as ajuda a crescer como pessoa porque "é uma forma de pensar no dia de amanhã quando forem idosas" faz com que "se sinta um membro da família", "mudou a sua maneira de ser e de ouvir o outro", “ ajudou a viver um dia de cada vez da melhor forma possível. Verificamos que todas as cuidadoras relataram um sentimento de satisfação em ver que a pessoa que cuidam se sente bem principalmente quando os vem felizes, a sorrir.

$\mathrm{O}$ aspeto que dá maior satisfação às entrevistadas no cuidado ao idoso vem reforçar a resposta ao item anterior invocando o fato dos idosos estarem contentes/confortáveis.

\section{DISCUSSÃO DOS RESULTADOS}

A amostra é caraterizada por mulheres cuidadoras de idosos institucionalizados no mesmo local, maioritariamente casadas, com idades de 50-55 anos e 15-20 anos de serviço, cuja habilitação literária predominante correspondente ao $6^{\circ}$ ano.

Em relação à decisão de trabalhar na área, a maioria evocou por necessidade de emprego e as outras referiu ser por gosto. Estes resultados estão em conformidade com os do estudo de Pereira e Marques (2014), onde as entrevistadas, na sua maioria, foram trabalhar para um Lar por questões de desempego e por gosto/apetência pelo cuidado prestado a idosos.

Todas as entrevistadas têm formação na área, nomeadamente: animação sociocultura, comunicação interpessoal, primeiros socorros e posicionamentos verbalizando que é útil para abordar/cuidar os idosos, ajudando-as a proporcionar o bem-estar dos idosos e dos próprios 
cuidadores. De igual modo, no estudo de Ferreira (2012) ficou demonstrado que as cuidadoras receberam formação, a maioria em contexto institucional, em áreas como geriatria e primeiros socorros, o que possibilita a melhoria da qualidade dos cuidados prestados, bem como a satisfação do cuidador no exercício das suas funções. De igual modo, todas as entrevistadas revelaram apreço por apostar mais na sua formação, mais concretamente nas seguintes áreas: higiene, Doença de Alzheimer/demência, Suporte Básico de Vida e primeiros socorros, cuidados paliativos e cuidados de enfermagem. Ferreira (2012) salienta que é fundamental que os cuidadores formais de idosos institucionalizados sintam necessidade de mais formação, sobretudo no que se refere aos idosos com demência. Perante a revisão da literatura e os dados evidenciados no presente estudo, torna se pertinente referir que Portugal é o quarto país da Organização para a Cooperação e Desenvolvimento Económico (OCDE) com mais casos de demência, com 19,9 casos por mil habitantes, um valor superior à média dos 35 países avaliados no Relatório Health at a Glance (2017). Ainda de acordo com os dados do mesmo Relatório, Portugal é o quarto país com mais casos de demência por mil habitantes, só superado pelo Japão $(23,3)$, Itália $(22,5)$ e Alemanha (20,2), o que justifica a formação dos cuidadores formais de idosos institucionalizados na área.

Quanto ao significado de ser idosos por parte das entrevistadas, verificamos que foram vários os pontos de vista, designadamente: voltar a ter tudo tal como quando se era novo, uma pessoa merecedora de respeito, sabedoria, pessoa que precisa de afeto e cuidados, voltar a ser criança e pessoa com limitações físicas. Estes relatos refletem uma visão positiva do ser idoso, ou seja, está implícita uma valorização da pessoa idosa. Pode dizer-se que as respostas obtidas estão em conformidade com o pressuposto de que a compreensão do processo de ser idoso não é uma conceção absoluta, uma vez que o significado real das transformações resultantes do processo de envelhecimento é singular, como o modo de pensar, de agir e de questionar, passando pela interpretação de cada pessoa face ao idoso e o contato que mantêm com o mesmo (Chambel, 2016).

Relativamente ao conceito de cuidar, houve consenso traduzido por dar carinho/apoio. Foram outros os pontos de vista das entrevistadas sobre o cuidar, tais como: transmitir confiança, um bem essencial), cuidar do 
corpo, mente e coração e saber escutar. Depreende-se, deste modo, que a convivência das cuidadoras com a pessoa idosa desenvolve-se num ambiente de afetividade, respeito, empatia e escuta ativa, aspeto corroborado por Collière (1999), para quem cuidar é manter a vida, garantindo a satisfação de um conjunto de necessidades vitais. Para Levinas (1961), o cuidar é uma atitude tão complexa que transcende ao plano patológico e abarca igualmente o ser humano sadio. O cuidar permeia todas as fases do desenvolvimento humano, na medida em que se cuida até ao fim de vida. Ou seja, é saber olhar o "rosto" do outro, como parte de um sujeito que nos é acessível, levando à aceitação plena da presença de um outro com o qual nos relacionamos e, por isso, obriga-nos a sair do nosso egoísmo. Por conseguinte, os relatos das entrevistadas revelam que a pessoa idosa institucionalizada se torna o núcleo do seu cuidado, preocupando-se não só com a sua saúde física, mas também com o seu bem-estar e felicidade.

Solicitou-se às entrevistadas que descrevessem a sua relação com os idosos a quem prestam cuidados, do que se apurou que algumas delas referiram ter uma relação de alegria e boa disposição, seguindo-se, em termos de representatividade, uma relação de respeito pela individualidade/vontade do idoso e uma relação que privilegia o cuidar holístico. Estes testemunhos estão em conformidade com os resultados encontrados por Chambel (2016), onde ficou demonstrado que os cuidadores formais de idosos institucionalizados mantêm uma relação de empatia com os utentes, procurando respeitar a sua individualidade e prestar cuidados num sentido holístico, o que se reverte em satisfação no trabalho.

No que concerne ao tipo de atividades/cuidados que as entrevistadas executam frequentemente, todas referiram que fazem um pouco de tudo, dando exemplos de algumas atividades/cuidados, designadamente: cuidados de higiene, vestir/despir, levantar/deitar, posicionar, cuidados da alimentação, atividades lúdicas e ajudar no transporte dos idosos. As atividades que mais prazer lhes dão realizar nos cuidados prestados aos idosos são: as atividades lúdicas, a alimentação e os cuidados de higiene. Estes resultados revelam uma satisfação geral, o que vai ao encontro dos resultados encontrados por Chambel (2016). 
Em relação às atividades nas quais as cuidadoras entrevistadas sentem mais dificuldades, constatou-se que estas variam entre o transporte dos idosos e o posicionar. Estes dados estão em conformidade com os encontrados por Pereira e Marques (2014), onde as dificuldades manifestadas pelos participantes do seu estudo na prestação de cuidados a idosos institucionalizados foram a deambulação, levante/posicionar e outros procedimentos ligados às diversas patologias que os mesmos possam apresentar, nomeadamente a Doença de Alzheimer e as variações de humor.

Em relação à satisfação profissional, verificou-se, em primeiro lugar, que, para todas as entrevistadas, a atividade de cuidadora traz-lhes satisfação pessoal, declarando que gostam do que fazem. Estes resultados estão em consonância com o referido por Sequeira (2007) e Chambel (2016), uma vez que, segundo os mesmos autores, o cuidar de idosos institucionalizados, quando realizado com prazer, revela-se em satisfação profissional e pessoal. Também Ferreira (2012), no seu estudo, constatou que as cuidadoras formais de idosos institucionalizados sentem satisfação profissional, demonstrando que o cuidado prestado se reverte em gratificação pessoal e que o contacto com os idosos resulta em aprendizagens pessoais.

$\mathrm{Na}$ maioria dos casos, as entrevistadas referem que o seu trabalho é apreciado por todos (idoso, família e direção), mas sobretudo pelos idosos. Neste âmbito, realça-se a importância de haver reconhecimento do trabalho desenvolvido pelas cuidadoras, o que se assume como um importante fator, pois quando os cuidadores se sentem reconhecidos profissionalmente estes, por inerência, sentem mais satisfação profissional (Sequeira, 2007). Importa também salientar que esse reconhecimento acaba por se refletir na positividade com que as entrevistadas demonstram em termos de crescimento pessoal e na satisfação que sentem ao saberem que a pessoa que cuidam se sente bem, tendo algumas delas manifestado sentir-se realizadas com os sorrisos e atitudes que os idosos têm, como forma de retribuição dos cuidados que elas lhes prestam. A este propósito, realçamos que todas as cuidadoras relataram que sentem satisfação em ver que a pessoa que cuidam se sente bem, está contente e que a sua maior satisfação é verem os idosos sorrir/felizes. 
Todas as entrevistadas sentem que prestar cuidados a idoso as tem ajudado a crescer como pessoa, pensar no dia de amanhã, ou seja, a veremse no lugar dos idosos, mudou a sua maneira de ser e de ouvir o outro, ensinou a viver um dia de cada vez. Neste âmbito, faz-se referência a Ferreira (2012) quando afirma que as cuidadoras formais de idosos institucionalizados do seu estudo também realçaram a projeção de si próprias no futuro como idosas e que passaram a encarar a vida de uma forma diferente, tentando viver um dia de cada vez, pensando que há pessoas que vivenciam situações bem diferentes e piores.

Quanto à satisfação das entrevistadas no cuidar do idoso, verificamos que o que lhes dá mais satisfação é sentirem que os idosos estão contentes/confortáveis. Estes resultados demonstram claramente que as cuidadoras entrevistadas se sentem realizadas com o trabalho que fazem, motivando-as a continuar a cuidar dos idosos, o que está em conformidade com o estudo de Colomé, Marqui, Jahn, Resta, Carli, Winck e Nora (2011) que, após questionarem os motivos que levaram um grupo de cuidadores que trabalham num Lar de idosos perceberam que a quase totalidade escolheu este trabalho motivado pelo respeito ao idoso, pelo desejo de fazer mais pelo ser humano, por vontade, amor e gosto de cuidar de pessoas idosas e sentir que as mesmas estão felizes e confortáveis. Para Ferreira (2012), o principal motor da motivação entre os cuidadores formais de idosos está particularmente relacionado com a possibilidade de prestar cuidados a quem precisa e ver que o resultado do seu cuidar é positivo.

\section{CONCLUSÃO}

Os resultados apurados permitiram dar resposta à questão de investigação e alcançar os objetivos delineados, constatando-se que, numa amostra constituída por doze cuidadoras de idosos institucionalizados, os motivos que as levaram a trabalhar na área foi por necessidade de emprego, gosto de trabalhar na área e de ajudar os outros. Todas têm formação na área, nomeadamente: animação sociocultural, geriatria, comunicação interpessoal, suporte básico de vida e primeiros socorros, posicionamentos e alimentação, bem como consideraram a formação útil para abordar/cuidar os idosos, o que as auxilia a proporcionar o bem-estar 
dos idosos e dos próprios cuidadores, levando-as a afirmar que gostariam de apostar mais na sua formação, mais concretamente, higiene, Doença de Alzheimer/demência, Suporte Básico de Vida, primeiros socorros, cuidados paliativos e cuidados em geral. Concluiu-se que os significados atribuídos pelas cuidadoras de ser idosos foram: voltar a ter tudo tal como quando se era novo, uma pessoa merecedora de respeito, sabedoria, pessoa que precisa de afeto e cuidados, voltar a ser criança e pessoa com limitações físicas. As entrevistadas entendem por cuidar dar carinho/apoio, transmitir confiança, um bem essencial, cuidar do corpo, mente e coração e saber escutar. A relação das cuidadoras com os idosos pauta-se por ser uma relação de alegria e boa disposição, uma relação de respeito pela individualidade/vontade do idoso, pela tentativa de se adaptar-se à personalidade de cada um.

No que se refere ao tipo de atividades/cuidados prestados que as entrevistadas executam frequentemente, as mesmas referiram que fazem um pouco de tudo, como: cuidados de higiene, vestir/despir, levantar/deitar, posicionar, cuidados da alimentação, atividades lúdicas, ajudar no transporte e apoio na deambulação dos idosos. Em relação às atividades nas quais as cuidadoras entrevistadas sentem mais dificuldades, constatou-se que estas variam entre o transporte dos idosos e posicionamentos.

No que concerne à satisfação profissional, concluiu-se que, para todas as entrevistadas, a atividade de cuidadora traz-lhes satisfação pessoal. $\mathrm{Na}$ maioria dos casos, as entrevistadas referem que o seu trabalho é apreciado por todos (idoso, família e direção), sobretudo pelos idosos. Todas as cuidadoras relataram que sentem satisfação em ver que a pessoa que cuidam se sente bem, sendo, para algumas, a sua maior satisfação ver os idosos sorrir/felizes.

Quanto às entrevistadas sentirem que prestar cuidados a idoso as tem ajudado a crescer como pessoa, constatou-se que todas consideram que sim, pois têm aprendido a colocar-se no lugar dos idosos, alteraram a sua forma de ser e de ouvir o outro e aprenderam a ver a vida de outra maneira.

Procurou-se igualmente saber o que dá mais satisfação às entrevistadas nos cuidados com os idosos, apurando-se que o que lhes dá maior satisfação é sentirem que os idosos estão contentes. 
Face a estes resultados, considera-se que se deve continuar a promover mais formação para os cuidadores formais de idosos institucionalizados, atendendo ao crescente aumento da esperança de vida e à dependência para as atividades de vida diária. Neste sentido é requerido um cuidar pautado pela excelência por parte dos cuidadores formais, como garantia de uma institucionalização que potencie ao máximo a qualidade de vida da pessoa idosa. Por outro lado, sugere-se que as próprias instituições geriátricas procurem auscultar os cuidadores formais, a fim de obterem um real conhecimento das suas necessidades, para que possam promover maior satisfação profissional, o que se traduzirá num cuidar mais humano e proficiente, porque, afinal, os idosos são um bem precioso e só cuida quem ama, só ama quem conhece, só conhece quem experimenta.

Foram várias as limitações do presente estudo tais como o facto de não se ter conseguido uma amostra mais dilatada, o que não permite fazer generalização dos resultados obtidos para outras amostras com as mesmas caraterísticas.

Assim, sugere-se que se dê continuidade a esta investigação, com uma amostra mais alargada, dando também "voz" aos idosos cuidados, de modo a poder-se também conhecer a sua perspetiva face aos cuidados recebidos.

\section{FONTES E BIBLIOGRAFIA}

Azevedo, L., \& Pereira, C. (2010). Vulnerabilidade ao Stress em Cuidadores Formais de Idosos Institucionalizados. VII Simpósio Nacional de Investigação em Psicologia. Braga.

Bardin, L. (2015). Análise de Conteúdo. Lisboa: edições 70.

Bauab, J. (2013). O Cotidiano, a Qualidade de Vida e a Sobrecarga de Cuidar de idosos em Processo Demencial de uma Unidade Escola Ambulatorial. (Dissertação de Mestrado) [em linha]. Universidade Federal de São Carlos. Disponível em: https://repositorio.ufscar.br/handle/ufscar/6868. Acedido a 15 de outubro de 2018.

Chambel, D.A.A. (2016). Trabalhar com idosos institucionalizados. Análise dos níveis de sobrecarga dos cuidadores formais. (Dissertação 
de Mestrado) [em linha]. Instituto Politécnico de Portalegre Escola Superior de Educação Escola Superior de Saúde de Portalegre. Disponível em:

https://comum.rcaap.pt/bitstream/10400.26/17845/1/Trabalhar\%20com $\% 20$ Idosos\%20Institucionalizados $\% 20 \mathrm{An} \% \mathrm{C} 3 \% \mathrm{~A} 1$ lises $\% 20 \mathrm{dos} \% 20 \mathrm{~N}$ iveis $\% 20 \mathrm{de} \% 20$ Sobrecarga $\% 20 \mathrm{de} \% 20$ Cuidadores $\% 20$ Formais.pdf.

Acedido a 15 de outubro de 2018.

Collière, M. F. (1999). Promover a vida. Lisboa: Lidel.

Colomé, I., Marqui, A., Jahn, A., Resta, D., Carli, R., Winck, M. \& Nora, T. (2011). Cuidar de idosos institucionalizados: características e dificuldades dos cuidadores. Revista Eletrónica de Enfermagem, 13 (2) 306-312.

Direção Geral de Saúde (2012). Plano Nacional de Saúde [em linha]. Disponível em: http://pns.dgs.pt/files/2012/02/Perfil_Saude_2013-0117.pdf . Acedido a 25 de setembro de 2018.

Ferreira, M. (2012). Ser Cuidador: Um Estudo sobre a Satisfação do Cuidador Formal de Idosos. Dissertação para a obtenção de Grau de Mestre em Educação Social ao Instituto Politécnico de Bragança.

Levinas, E. (1961). Totalidade e Infinito. Traduzido por José Pinto Ribeiro. Porto: Edições 70.

Martins, R., Santos, P., Andrade, A. (2015). Satisfação com a vida em idoso: prevalência e determinantes, Gestão e Desenvolvimento, 23, 107. Pereira, S.A.S., Marques, E.M.B.G. (2014). Dificuldades dos Cuidadores Formais de Idosos Institucionalizados, INFAD Revista de Psicologia, 1, 133-140.

Sequeira, C. (2010). Cuidar de Idosos com Dependência Física e Mental. Lisboa: Lidel, Edições Técnicas Lda.

Wu, C. (2009). Learning to be a Family Caregiver for Severely Debilitated Stroke Survivors during the First Year in Taiwan. Dissertação de Doutoramento: Universidade de Iowa [em linha]. Disponível em: https://ir.uiowa.edu/etd/451/. Acedido em 25 de setembro de 2018. 
Magda Guerra, Isabel Martins, Dina Santos, J. Veiga, R. Moitas, R. Silva

Anexo 1

Tabela 1 - Estrutura da entrevista

\begin{tabular}{|c|c|c|}
\hline CATEGORIAS & OBJETIVOS & $\begin{array}{r}\text { QUESTÕ̃ES } \\
\end{array}$ \\
\hline $\begin{array}{c}\text { Caraterização } \\
\text { sociodemográfica }\end{array}$ & $\begin{array}{c}\text { Caraterizar a amostra } \\
\text { em estudo }\end{array}$ & $\begin{array}{l}\text { Género? } \\
\text { Idade? } \\
\text { Estado civil? } \\
\text { Habilitações literárias? } \\
\text { Anos de serviço neste Lar? }\end{array}$ \\
\hline $\begin{array}{l}\text { Formação do } \\
\text { cuidador }\end{array}$ & $\begin{array}{l}\text { Identificar se } \text { os } \\
\text { entrevistados possuem } \\
\text { formação na área do } \\
\text { cuidado aos idosos. } \\
\begin{array}{l}\text { Compreender se os } \\
\text { mesmos } \\
\text { compreendem que a } \\
\text { formação é útil. }\end{array} \\
\end{array}$ & $\begin{array}{l}\text { O que o levou a trabalhar nesta área? } \\
\text { Possui formação/curso para o cuidado ao } \\
\text { idoso? Se sim, em que áreas? } \\
\text { Sente que as mesmas foram úteis? De que } \\
\text { forma? } \\
\text { Gostaria de apostar mais na sua formação? Em } \\
\text { que áreas? } \\
\text { Qual a habilitação académica que possui? }\end{array}$ \\
\hline $\begin{array}{l}\text { Conceções } \\
\text { de } \\
\text { "cuidar/cuidado" } \\
\text { ao idoso }\end{array}$ & $\begin{array}{l}\text { Identificar } \mathrm{a}(\mathrm{s}) \\
\text { representação (ões) } \\
\text { sobre o conceito de } \\
\text { cuidar/cuidado. } \\
\text { Perceber se a forma } \\
\text { como o cuidador vê o } \\
\text { idoso influencia o seu } \\
\text { cuidado. }\end{array}$ & $\begin{array}{l}\text { Explicite o seu ponto de vista sobre, o que é ser } \\
\text { "idoso"? } \\
\text { O que entende por "cuidar"? } \\
\text { Como descreve a sua relação com o idoso? } \\
\text { Para si o que acha que as pessoas pensam } \\
\text { quando se fala de velho/velhice? }\end{array}$ \\
\hline $\begin{array}{l}\text { Atividades } \\
\text { executadas }\end{array}$ & $\begin{array}{l}\text { Identificar as atividades } \\
\text { desenvolvidas } \\
\text { Perceber como os } \\
\text { entrevistados encaram o } \\
\text { desempenho das suas } \\
\text { atividades. }\end{array}$ & $\begin{array}{l}\text { Que tipo de atividades/cuidados que executa } \\
\text { frequentemente? } \\
\text { Qual a atividade lhe dá mais prazer? } \\
\text { Qual a atividade mais difícil de realizar? }\end{array}$ \\
\hline $\begin{array}{l}\text { Dificuldades } \\
\text { sentidas }\end{array}$ & $\begin{array}{lr}\text { Identificar } & \text { as } \\
\text { dificuldades de cada } \\
\text { profissional no exercício } \\
\text { da sua profissão. }\end{array}$ & $\begin{array}{l}\text { Qual a maior dificuldade com que se deparou } \\
\text { no seu trabalho? } \\
\text { Qual o momento mais complicado com que se } \\
\text { deparou no exercício da sua profissão? }\end{array}$ \\
\hline $\begin{array}{l}\text { Satisfação } \\
\text { profissional }\end{array}$ & $\begin{array}{l}\text { Identificar } \\
\text { fatores/variáveis de } \\
\text { satisfação do cuidador } \\
\text { provenientes da sua vida } \\
\text { profissional }\end{array}$ & $\begin{array}{l}\text { Sente que a sua profissão influencia de forma } \\
\text { negativa a sua vida privada? Se sim, indique } \\
\text { uma situação. } \\
\text { Considera que a sua atividade de cuidador lhe } \\
\text { trás benefícios pessoais? Se sim, quais } \\
\text { benefícios. } \\
\text { Dá-lhe satisfação em perceber que a pessoa de } \\
\text { quem cuida se sente bem? Em que aspetos? } \\
\text { Sente que o seu trabalho é apreciado pelo idoso } \\
\text { e/ou família? Pela direção e restante equipa? } \\
\text { Dá-lhe satisfação em perceber que a pessoa de } \\
\text { quem cuida se sente bem? Em que aspetos? } \\
\text { Sente que prestar cuidados tem ajudado a } \\
\text { crescer como pessoa? Dê um exemplo. }\end{array}$ \\
\hline
\end{tabular}


Tabela 2 - Categoria Formação do cuidador

\begin{tabular}{|c|c|c|c|c|}
\hline Categoria & Subcategorias & Indicadores & \begin{tabular}{|l|} 
Unidades de registo \\
\end{tabular} & $\mathrm{n}$ \\
\hline \multirow{13}{*}{$\begin{array}{c}\text { Caraterização } \\
\text { sociodemográfica }\end{array}$} & Género & Feminino & E1, E2, E3, E4, E5, E6, E7, E8, E9, & 12 \\
\hline & Idade & $35-39$ & E2, E4, E11 & 3 \\
\hline & & $40-44$ & E1, E7 & 2 \\
\hline & & $45-49$ & E9, E10 & 2 \\
\hline & & $50-55$ & E3, E5, E6, E8, E12 & 5 \\
\hline & Estado civil & Solteira & E11 & 1 \\
\hline & & Casada & $\begin{array}{l}\text { E1, E2, E3, E4, E5, E6, E7, E8, E9, } \\
\text { E10, E12 }\end{array}$ & 11 \\
\hline & Habilitaç̃es & $6^{\circ}$ ano & E2, E3, E4, E5, E7, E10, E11, E12 & 8 \\
\hline & literárias & 9 ano & & 1 \\
\hline & & $12^{\circ}$ ano & E1, E6, E9 & 3 \\
\hline & & & E1, E6, E9 & 3 \\
\hline & Anos de & $5-9$ anos & E8 & 1 \\
\hline & serviço & $\begin{array}{l}10-14 \text { anos } \\
15-20 \text { anos }\end{array}$ & E2, E3, E4, E5, E7, E10, E11, E12 & 8 \\
\hline \multirow{16}{*}{$\begin{array}{l}\text { Formação } \\
\text { do cuidador }\end{array}$} & Decisão para & Necessidade & E1, E2, E3, E5, E8, E9, E11, E12 & 8 \\
\hline & $\begin{array}{l}\text { Trabalhar na } \\
\text { área }\end{array}$ & $\begin{array}{l}\text { de emprego } \\
\text { Gosto pela área }\end{array}$ & E4. E6. E7, E10 & 4 \\
\hline & Possuir algum & Animador Sociocultural & E1 & 12 \\
\hline & sobre o cuidado & Primeiros socorros & E7, E8, E9, E10, E12 & \\
\hline & áreas de & Posicionamentos & E3, E4, E5, E11 & \\
\hline & & Geriatria & E2, E6 & \\
\hline & & Comunicação & E3 & \\
\hline & & $\begin{array}{l}\text { interpessoal } \\
\text { Apoio à comunidade }\end{array}$ & E2, E5, E8, E12 & \\
\hline & Utilidade das & Formação útil para & E1, E2, E3, E4, E5, E6, E7, E8, & 12 \\
\hline & formações & $\begin{array}{l}\text { abordar/cuidar os } \\
\text { idosos }\end{array}$ & E9, E10, E11, E12 & \\
\hline & \multirow{6}{*}{$\begin{array}{lr}\text { Apostar } & \text { mais } \\
\text { na } & \text { sua } \\
\text { formação } & \end{array}$} & Higiene & $\begin{array}{l}\text { E1, E6, E8, } \\
\text { E11 }\end{array}$ & 4 \\
\hline & & $\begin{array}{l}\text { Doença de } \\
\text { Alzheimer/demência }\end{array}$ & $\begin{array}{l}\text { E1, E2, E3, E4, E5, E6, E7, E8, E9 } \\
\text { E11, E12 }\end{array}$ & 11 \\
\hline & & Suporte Básico de & & 5 \\
\hline & & $\begin{array}{l}\text { Vida e primeiros } \\
\text { socorros }\end{array}$ & E1, E4, E6, E7, E9 & \\
\hline & & Cuidados Paliativos & $\begin{array}{l}\text { E1, E2, E3, E4, E5, E6, E7, E8, E9, } \\
\text { E12 }\end{array}$ & 11 \\
\hline & & Cuidados & E8 & 1 \\
\hline
\end{tabular}


Magda Guerra, Isabel Martins, Dina Santos, J. Veiga, R. Moitas, R. Silva

Tabela 3 - Categoria: Conceções de "cuidar/cuidado" ao idoso

\begin{tabular}{|c|c|c|c|}
\hline Subcategorias & Indicadores & Unidades de registo & $\mathbf{n}$ \\
\hline \multirow[t]{5}{*}{$\begin{array}{l}\text { Significado de } \\
\text { ser idoso }\end{array}$} & $\begin{array}{l}\text { Voltar a ter tudo como } \\
\text { quando era mais novo }\end{array}$ & E1, E10 & 2 \\
\hline & $\begin{array}{l}\text { Pessoa com muita } \\
\text { sabedoria e merecedora } \\
\text { de respeito }\end{array}$ & E2, E3, E8, E9, E11, E12 & 6 \\
\hline & $\begin{array}{l}\text { Pessoa que precisa de } \\
\text { afeto e cuidados }\end{array}$ & E4, E5 & 2 \\
\hline & Voltar a ser criança & E6 & 1 \\
\hline & $\begin{array}{l}\text { Pessoa com } \\
\text { limitações físicas } \\
\end{array}$ & E7 & 1 \\
\hline \multirow{3}{*}{$\begin{array}{l}\text { Conceito de } \\
\text { cuidar }\end{array}$} & Transmitir confiança & E1, E2, E6, & 3 \\
\hline & $\begin{array}{l}\text { Cuidar do corpo, mente } \\
\text { e coração }\end{array}$ & 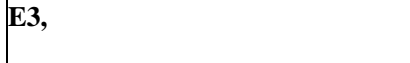 & 1 \\
\hline & Dar carinho/apoio & E4; E5, E7, E8, E9, E10, E11, E12 & 8 \\
\hline \multirow{3}{*}{$\begin{array}{l}\text { Relação com o } \\
\text { idoso }\end{array}$} & Alegria e boa disposição & E1, E3, E4, E5, E8, E9, E12 & 7 \\
\hline & $\begin{array}{l}\text { Respeito pela } \\
\text { individualidade/ } \\
\text { vontade }\end{array}$ & E2, E6, E10, E11 & 4 \\
\hline & Cuidar geral & E7 & 1 \\
\hline \multirow{2}{*}{$\begin{array}{l}\text { Opinião das } \\
\text { pessoas quando } \\
\text { se fala de } \\
\text { velho/velhice }\end{array}$} & Pessoa reformada & E1, E2, E4, E5, E8, E9, E11, E12 & 8 \\
\hline & $\begin{array}{l}\text { Pessoa com as suas } \\
\text { capacidades diminuídas }\end{array}$ & E3, E6, E7, E10 & 4 \\
\hline
\end{tabular}




\section{Tabela 4 - Atividades executadas}

\begin{tabular}{|c|c|c|c|c|}
\hline Categoria & Subcategorias & Indicadores & Unidades de registo & $\mathbf{n}$ \\
\hline \multirow[t]{6}{*}{$\begin{array}{l}\text { Atividades } \\
\text { executadas }\end{array}$} & $\begin{array}{l}\text { Tipo de atividades/ } \\
\text { cuidados que executa } \\
\text { frequentemente }\end{array}$ & $\begin{array}{l}\text { Higiene } \\
\text { Vestir/Despir } \\
\text { Levantar/Deitar } \\
\text { Posicionar } \\
\text { Atividades Lúdicas } \\
\text { Alimentação } \\
\text { Transporte e apoio } \\
\text { na deambulação }\end{array}$ & $\begin{array}{l}\text { E1, E2, E3, E4, E5, E6, } \\
\text { E7, E8, E9, E10, E11, E12 } \\
\text { E1, E2, E3, E4, E5, E6, } \\
\text { E7, E8, E9, E10, E11, E12 } \\
\text { E1, E2, E3, E4, E5, E6, } \\
\text { E7, E8, E9, E10, E11, E12 } \\
\text { E1, E2, E3, E4, E5, E6, } \\
\text { E7, E8, E9, E10, E11, E12 } \\
\text { E1, E2, E3, E4, E5, E6, } \\
\text { E7, E8, E9, E10, E11, E12 } \\
\text { E1, E2, E3, E4, E5, E6, } \\
\text { E7, E8, E9, E10, E11, E12 } \\
\text { E1, E2, E3, E4, E5, E6, } \\
\text { E7, E8, E9, E10, E11, E12 }\end{array}$ & 12 \\
\hline & \multirow[t]{3}{*}{$\begin{array}{l}\text { Atividade que } \\
\text { dá mais prazer }\end{array}$} & Atividades lúdicas & E1, E6, E7, E9, E12 & 5 \\
\hline & & Alimentação & E2, E3, E10, E11 & 4 \\
\hline & & Higiene & E4, E5, E8, & 3 \\
\hline & \multirow{2}{*}{$\begin{array}{l}\text { Atividade em que sente } \\
\text { mais } \\
\text { dificuldade em } \\
\text { realizar }\end{array}$} & Transporte & E2, E3, E6, E10, E11, E12 & 6 \\
\hline & & Posicionar & E1, E4, E5, E7, E8, E9 & 6 \\
\hline
\end{tabular}


Magda Guerra, Isabel Martins, Dina Santos, J. Veiga, R. Moitas, R. Silva

Tabela 5 - Dificuldades sentidas

\begin{tabular}{|c|c|c|c|c|}
\hline Categorias & Subcategorias & Indicadores & $\begin{array}{l}\text { Unidades de } \\
\text { registo }\end{array}$ & $\mathbf{n}$ \\
\hline $\begin{array}{l}\text { Dificuldades } \\
\text { sentidas }\end{array}$ & $\begin{array}{l}\text { Qual a maior } \\
\text { dificuldade } \\
\text { com que se } \\
\text { deparou no seu } \\
\text { trabalho? } \\
\text { Momento mais } \\
\text { complicado que } \\
\text { já se deparou } \\
\text { no da } \\
\text { exercício da } \\
\text { sua profissão }\end{array}$ & $\begin{array}{l}\begin{array}{l}\text { Falta de cooperação } \\
\text { entre colegas }\end{array} \\
\text { Culpabilização de má } \\
\text { prestação de cuidados } \\
\text { Queda } \\
\text { Engasgamento do idoso } \\
\text { Primeiro banho }\end{array}$ & $\begin{array}{l}\text { E1, E2, E3, E4, E5, } \\
\text { E6, E7, E8, E9, } \\
\text { E10, E11, E12, } \\
\text { E1, E3, E5, E6, } \\
\text { E10, E11 } \\
\text { E4, E8, E9, } \\
\text { E12 } \\
\text { E7 } \\
\text { E2 }\end{array}$ & $\begin{array}{l}1 \\
1\end{array}$ \\
\hline
\end{tabular}


Tabela 6 - Categoria: Satisfação profissional

\begin{tabular}{|c|c|c|c|c|}
\hline Categoria & Subcategorias & Indicadores & $\begin{array}{l}\text { Unidades de } \\
\text { registo }\end{array}$ & $\mathbf{n}$ \\
\hline \multirow{9}{*}{$\begin{array}{l}\text { Satisfação } \\
\text { profissional }\end{array}$} & $\begin{array}{l}\text { Sentir que a } \\
\text { profissão } \\
\text { influência de } \\
\text { forma negativa } \\
\text { a sua vida privada }\end{array}$ & $\begin{array}{l}\text { Pouco convívio } \\
\text { com os filhos } \\
\text { Sempre positiva } \\
\text { Ao nível da saúde }\end{array}$ & $\begin{array}{l}\text { E2, E6, E8, E10, } \\
\text { E9, E11 } \\
\text { E1, E3, E4 } \\
\text { E5, E7, E12 }\end{array}$ & $\begin{array}{l}3 \\
3\end{array}$ \\
\hline & \begin{tabular}{|lr} 
Atividade & de \\
cuidador & traz \\
satisfação pessoal
\end{tabular} & Sim & $\begin{array}{l}\text { E1, E2, E3, E4, } \\
\text { E5, E6, E7, E8, } \\
\text { E9, E10, E11, } \\
\text { E12 }\end{array}$ & 12 \\
\hline & \multirow[t]{2}{*}{$\begin{array}{l}\text { Trabalho } \\
\text { apreciado pelo } \\
\text { idoso e pela } \\
\text { família }\end{array}$} & $\begin{array}{l}\text { Sim } \\
\text { (pela família) } \\
\text { Não } \\
\text { (pela família) }\end{array}$ & $\begin{array}{l}\text { E1, E2, E5, E6, E7, } \\
\text { E8, E12 } \\
\text { E3, E4, E9, E10, } \\
\text { E11 }\end{array}$ & $\begin{array}{l}7 \\
5\end{array}$ \\
\hline & & \begin{tabular}{|l|} 
Pelos \\
idosos
\end{tabular} & $\begin{array}{l}\text { E1, E2, E3, E4, E5, } \\
\text { E6, E7, E8, E9, } \\
\text { E10, E11, E12 }\end{array}$ & 12 \\
\hline & \multirow{2}{*}{$\begin{array}{l}\text { Trabalho } \\
\text { apreciado pelo } \\
\text { idoso e pela } \\
\text { direção }\end{array}$} & Sim & $\begin{array}{l}\text { E1, E3, E6, E7, E8, } \\
\text { E9, E10, E11, E12 }\end{array}$ & 9 \\
\hline & & Não sabe & E2, E4, E5 & 2 \\
\hline & $\begin{array}{lr}\text { Prestar } & \text { cuidados } \\
\text { ao idoso } & \text { ajuda a } \\
\text { crescer } & \text { como } \\
\text { pessoa } & \end{array}$ & Sim & $\begin{array}{l}\text { E1, E2, } \\
\text { E3, E4, E5, } \\
\text { E6, E7, E8, } \\
\text { E9, E10, } \\
\text { E11, E12 }\end{array}$ & 12 \\
\hline & $\begin{array}{l}\text { Satisfação em ver } \\
\text { que a pessoa que } \\
\text { cuida se sente } \\
\text { bem }\end{array}$ & Sim & $\begin{array}{l}\text { E1, E2, } \\
\text { E3, E4, E5, } \\
\text { E6, E7, E8, } \\
\text { E9, E10, } \\
\text { E11, E12 }\end{array}$ & 12 \\
\hline & $\begin{array}{l}\text { Nos cuidados } \\
\text { com os idosos o } \\
\text { que dá mais } \\
\text { satisfação }\end{array}$ & $\begin{array}{l}\text { Sentir que estão } \\
\text { contentes/ } \\
\text { confortáveis }\end{array}$ & $\begin{array}{l}\text { E1, E2, E3, E4, E5, } \\
\text { E6, E7, E8, E9, } \\
\text { E10, E11, E12 }\end{array}$ & 12 \\
\hline
\end{tabular}

